\title{
Alaska, USA
}

4 Gregory C. Wiles*1,3, Joshua Charlton ${ }^{1}$, Rob J.S. Wilson ${ }^{2,3}$, Rosanne D. D’Arrigo ${ }^{3}$, Brian Buma , John Krapek ${ }^{5}$, Benjamin V. Gaglioti ${ }^{3,6}$, Nicholas Wiesenberg ${ }^{1}$ and Rose Oelkers ${ }^{3}$

${ }^{1}$ Department of Earth Sciences, The College of Wooster, Wooster, OH, USA

8 (gwiles@wooster.edu, jcharlton19@wooster.edu, nwiesenberg@wooster.edu; Tel: 330-263-

9 2298, FAX: 330-263-2249); ${ }^{2}$ School of Earth and Environmental Sciences, University of St.

10 Andrews St Andrews, UK. (rjsw@st-andrews.ac.uk); ${ }^{3}$ Tree Ring Lab, Lamont-Doherty Earth

11 Observatory Palisades, NY 10964, USA (rdd@1deo.columbia.edu, bengaglioti@gmail.com and

12 roelkers91@gmail.com); Department of Integrative Biology, University of Colorado, Denver,

131151 Arapahoe, Denver, CO 80204, USA (brian.buma@ucdenver.edu); ${ }^{5}$ Department of Natural

14 Sciences, University of Alaska Southeast, Juneau, Alaska 99801, USA (jpkrapek@gmail.com);

$15{ }^{6}$ Water and Environmental Research Center, Institute of Northern Engineering, University of

16 Alaska Fairbanks, Fairbanks, AK 99775.

$18 *$ Corresponding author 


\section{Abstract}

33 This is the first study to generate and analyze the climate signal in Blue Intensity (BI) tree-ring

34 chronologies from Alaskan yellow-cedar (Callitropsis nootkatensis D. Don; Oerst. ex D.P.

35 Little). The latewood BI chronology shows a much stronger temperature sensitivity than ring-

36 widths (RW), and thus can provide information on past climate. The well-replicated BI

37 chronology exhibits a positive January-August average maximum temperature signal for 1900-

38 1975, after which it loses temperature sensitivity following the 1976/77 shift in northeast Pacific

39 climate. The positive temperature response appears to recover and remains strong for the most

40 recent decades although the coming years will continue to test this observation. This temporary

41 loss of temperature sensitivity from about 1976 to 1999 is not evident in RW or in a change in

42 forest health, but is consistent with prior work linking cedar decline to warming. A confounding

43 factor is the uncertain influence of a shift in color variation from the heartwood/sapwood

44 boundary. Future expansion of the yellow-cedar BI network and further investigation of the

45 influence of the heartwood/sapwood transitions in the BI signal will lead to a better

46 understanding of the utility of this species as a climate proxy.

47 Key words: Yellow cedar, blue intensity, tree rings, dendroclimatology, Alaska 


\section{1. Introduction:}

54 Climate-driven, abiotic stresses are emerging as a major driver of forest decline in North

55 America (Cohen et al., 2016; Buma et al., 2017). Forest decline is defined as the loss of tree

56 vigor and eventual mortality triggered by complex biotic and abiotic factors (Manion and

57 Lachance 1992). Abiotic forest decline is a complex disorder driven by various non-living

58 physical stresses, including climate change, on a forest stand that results in growth decline and

59 can lead to mortality. Affected trees may recover once the stresses are removed. Identifying the

60 response of ecosystems to varying rates of climate change is a challenge as species may respond

61 linearly or non-linearly to anthropogenic warming as well as to the natural internal climate

62 dynamics of the North Pacific (Krapek et al., 2017). In the coastal northeast Pacific, of particular

63 interest are the Pacific related decadal fluctuations (ie., the Pacific Decadal Oscillation; PDO)

64 that dominate many aspects of the climate and ecosystems and have persisted for increasingly

65 long intervals over the observational record since CE 1900 (Boulton and Lenton, 2015; Gaglioti

66 et al., 2019). This decadal variability is superimposed on contemporary warming and has been

67 observed throughout the Little Ice Age ( CE 1250-1850; Wilson et al., 2007).

Decadal shifts have been recognized in climate data, climate indices and biological time

69 series (Overland et al., 2008). Determining the causes of shifts in North Pacific climate has been

70 an ongoing challenge, in part due to the large number of both instrumental and proxy time series

71 available, all of which capture different aspects of climate system on various timescales (ENSO,

72 decadal and century-scale warming). Efforts to extract the decadal signal from sea surface

73 temperature data suggest that in addition to the positive shift in PDO in 1975/76, a negative shift

74 occurred in 1998/99, although it may be too early to label this episode as a "regime shift" (Ding

75 et al., 2013; McAfee, 2014, 2016; Wills et al., 2018). 
Here we examine the climate response of a well-replicated tree-ring chronology of

yellow-cedar (Callitropsis nootkatensis

D. sites near Juneau, Alaska (Table 1, Fig. 1). Yellow-cedar is an economically and culturally important species, which grows along the northwest coast of North America (Oakes, 2018; Hennon et al., 2016). The wood is strong and resistant to decay, used for canoe paddles and in carvings, and its inner bark is utilized for fiber in weavings. The three sites composited in this study have had limited evidence of cultural modification with the exception of one of them, Cedar Lake, which shows evidence of bark stripping on a few trees that have been utilized over the past few decades to a century. Our three sites have been discussed in previous publications including analyses of ring-width data (RW) from Cedar Lake (Beier et al., 2008) and investigations of forest ecology at all three sites (Krapek et al., 2017). Krapek and Buma (2017) showed that the timing of yellow-cedar establishment in these stands occurred during cool/wet intervals of the Little Ice Age and that cedar could not colonize where other species outcompeted this long-lived, slow growing and slow migrating species.

Yellow cedar has been the subject of intense study primarily because of the phenomenon of widespread decline of this species in southeastern Alaska, which is relatively well understood. In the early 1980s, foresters (led largely by the National Forest Service in Juneau, Alaska) ruled out various pathogens and other abiotic factors (Hennon et al. 2006, 2012, 2016; Schaberg et al., 2008). The current leading hypothesis for the decline has been factors related to warming temperatures. Earlier spring snowmelt, and the associated shift in the transition from snow to rain, both lead to a loss of spring snowpack, which can contribute to freezing of rootlets and to decline. Snowpack provides insulation from cold surface air temperatures, protecting vulnerable small roots from frost events especially when shallow root dehardening occurs in wet soils 
99 (Schaberg et al., 2008, 2011; Hennon et al. 2012, 2016). Extensive work has been done testing

100 this hypothesis and exploring the forest dynamics and ecology associated with the decline

101 (Oakes et al., 2014, 2015; Krapek and Buma, 2017; Krapek et al., 2017) driven by concerns of

102 species loss and determination of whether the species is endangered (Buma et al., 2017; Barrett

103 and Pattison, 2017, Bidlack et al., 2017).

104 Dendroclimatic studies of RW in southeast Alaska have shown that the growth response

105 of yellow-cedar can be spatially and temporally complex (Beier et al., 2008; Wiles et al., 2012)

106 and, in general, results have not been promising for climate reconstruction. Beier et al. (2008)

107 analyzed RW from declining cedar sites in southeast Alaska and from the healthy stand at Cedar

108 Lake, one of our study sites. At Cedar Lake, they noted a general decrease in RW over the past

109 several decades, whereas at sites that were experiencing substantial decline and tree death,

110 farther to the southeast of Juneau, a reduced-competition growth release in surviving trees was

111 detected. Another RW study examined two healthy yellow-cedar stands in Glacier Bay National

112 Park and Preserve (Wiles et al., 2012). This latter work showed a marked nonstationary response

113 to climate with a notable shift in temperature sensitivity from positive (more growth with warmer

114 temperatures) to negative (less growth with warmer temperatures) after CE 1950, presumably as

115 warming occurred (Wiles et al. 2012). Wiles et al. (2012) also documented decreased radial

116 growth for decades but without any visible evidence of decline in the crowns of the trees.

117 Similarly, Hennon et al. (1990) observed a decrease in RW, sometimes for decades, prior to

118 noticeable decline in the outward appearance of the trees.

119 In a regional study examining yellow-cedar health across its entire range (Buma et al.,

120 2017) identified a critical threshold of mean winter temperatures above $0^{\circ} \mathrm{C}$ as snow turns to rain

121 (Buma et al., 2017) and rootlets become more susceptible to frost damage. Once winter 
122 temperatures sufficiently warm, frosts may be less frequent and snowpack will not be as crucial a

123 factor in protecting root systems. This appears to be the case at the southern range of yellow-

124 cedar (Buma, 2018) in Washington and Oregon where healthy stands are flourishing. This

125 previous work provides a context for the present study, as our sites are entering the zone where

126 mean winter temperatures are between $-2^{\circ}$ and $+2^{\circ} \mathrm{C}$ as mapped by Buma et al. (2017) and are

127 thus susceptible to future decline as warming proceeds.

128 Previous dendroclimatic investigations along the Gulf of Alaska (GOA) have used tree

129 rings from coastal sites for climate reconstruction focusing primarily on mountain hemlock RW

130 (Tsuga mertensiana (Bong.) Carr.; Barclay et al., 1999; D’Arrigo et al., 2001; Wilson et al.,

131 2007; Wiles et al. 2014). More recently BI records are showing promise for generating robust

132 climate reconstructions along the GOA (Wilson et al., 2017) and in the Yukon (Wilson et al, in

133 press). Thus far, BI chronologies for the GOA have only been developed for mountain hemlock

134 (Wilson et al., 2017). Wilson et al. (2017) used the delta BI (dBi; latewood BI (LBi) subtracted

135 from the earlywood $\mathrm{BI}(\mathrm{EBi})$ values) parameter to reconstruct climate, noting the stronger

136 relationship between summer temperature and $\mathrm{dBi}$ than with LBi or EBi for mountain hemlock.

137 Here we present the first BI tree-ring series for yellow-cedar and examine the strength

138 and stability of its climate signal. Both RW and LBi chronologies for yellow-cedar were

139 examined for their potential for climate reconstruction and our results are interpreted within the

140 context of the yellow-cedar decline outlined above (Buma et al., 2017; Hennon et al., 2016). We

141 generated ring-width (RW) and blue intensity (BI) measurements to document the climate

142 response over the past several centuries. Latewood blue intensity (LBi) is a similar tree-ring

143 measurement to maximum latewood density (MXD). BI measurements, in general, reflect the

144 combined hemi-cellulose, cellulose and lignin content in the latewood which are key components 
145 of relative density (Björklund et al., 2014; Rydval et al., 2014). The utility of LBi as a summer

146 temperature proxy has been shown to improve climate reconstruction from multiple high

147 elevation and high latitude sites (Björklund et al., 2014, 2015; Campbell et al., 2007; Dolgova,

148 2016; Rydval et al., 2014, 2017; Wilson et al., 2014) and the use of dBi from the Gulf of Alaska

149 (Wilson et al., 2017). Significantly, blue intensity is a much less expensive parameter to generate

150 than MXD. One downside however, is that LBi chronologies generally require a larger sample

151 size than MXD to generate a robust mean chronology (Björklund et al., 2014; Wilson et al.,

152 2014, 2017).

\section{2. Methods}

155 Trees were cored at the aforementioned three sites near Juneau: Cedar Lake, Bridget Cove and 156 East Glacier (Fig. 1). The sites range in elevation from 110 to over $480 \mathrm{~m}$ (Table 1). For the 157 Cedar Lake site, cores and ring-width data were obtained from other researchers (Beier et al., 158 2008; Krapek et al., 2017) and combined with our collections from the summers of 2016 and 1592017 (Charlton et al., 2017). The tree cores were immersed in acetone for 72 hours to remove 160 resins in the wood (Rydval et al., 2014; Fuentes et al., 2018), then glued onto wood mounts and 161 sanded to a high polish. An Epson V850 pro scanner, using an IT8.7/2 calibration card in 162 conjunction with SilverFast scanning software was used to scan the samples at a resolution of 1632400 dpi. Scanning was done with a nonreflective black box covering the scanner window. BI 164 measurements were made using CDendro 8.1 and CooRecorder 8.1 (Larsson, 2016). Previously 165 generated ring-width chronologies facilitated calendar dating, and COFECHA (Holmes, 1983) 166 was used as a final quality control for the dating of the RW and LBi measurements. 
Since BI measurements are color based, discoloration of the wood presents challenges.

168 One is the presence of a heartwood/sapwood boundary, which can cause a color shift in some

169 species that may impose a trend bias in the BI series (Björklund et al., 2014; 2015). In most of

170 the yellow-cedar cores we did not observe a strong color difference, although a subtle change

171 was noted in some series that might be enough to influence the measured values. To investigate

172 potential color change, we counted the number of rings at the transition from heartwood to

173 sapwood where we were able to discern the transition; counts ranged from 16 to 50 years in the

$174 \sim 10 \%$ of samples in which we could detect the transition. The blue intensity parameters that

175 were evaluated included: LBi, earlywood BI (EBi) and the derived dBi (McCarroll et al., 2002;

176 Björklund et al., 2014, 2015; Rydval et al., 2014; Wilson et al., 2017). In our yellow cedar series,

177 EBi and LBi values are highly correlated with one another ( $\mathrm{r}=0.82$ for $1900-2014)$. The

178 application of $\mathrm{dBi}$ in the case of such a strong inter-correlation can lead to a loss in climate signal

179 (Björklund et al. 2014). The uniform density between the earlywood and latewood illustrated in

180 this high correlation is consistent with known wood properties that make the yellow cedar

181 desirable for its smoothly carved surfaces (Hennon et al., 2016). Given the high correlation

182 between the early and latewood measurements, and our strong results for our climate analyses

183 using $\mathrm{LBi}$, we focused herein on only the LBi and RW signals from yellow-cedar for this paper.

184 We combined the individual series from the three sites into a regional master chronology

185 based on the strong correlations and coherent low frequency features among the sites. The

186 combined final RW and LBi chronologies are well replicated and both incorporate 179 series

187 from 113 trees. Although individual sites have trees that date back to CE 1114 (East Glacier;

188 Table 1) we examine the combined record back to CE 1400 based on a critical Expressed 
189 Population Signal (EPS) of $>0.85$ (Fig. 2a; Wigley et al, 1984). The EPS is a measure of how 190 well a sample of tree-ring data (ie., number of tree ring series) represents an ideal population. 191 We followed the methodology of Wilson et al. (2017) in processing the ring-width and 192 LBi records into chronologies. Tree-ring series were standardized using the signal-free (SF), age 193 dependent spline (ADS) approach described in Melvin et al. (2007), and Melvin and Briffa

194 (2008, 2014; Fig. 2a). We used the signal free software RCSigFree, a freeware program 195 developed at the Tree-Ring Lab of the Lamont-Doherty Earth Observatory 196 (http://www.ldeo.columbia.edu/tree-ring-laboratory/resources/software) that is based on the 197 program ARSTAN (Cook, 1985). The SF approach was used because of the complex growth 198 trends recognized in the individual tree ring series; both Wilson et al., (2017; in press) and 199 Buckley et al. (2018) similarly used SF standardization with favorable results.

201 (Tmax, CRU TS4.01; Harris et al., 2014; Fig. 3). The temperature series was calculated by 202 averaging gridded data from within the coordinates $56^{\circ}-62^{\circ} \mathrm{N}, 130^{\circ}-140^{\circ} \mathrm{W}$ (Fig. 1) for the 203 CE 1900-2014 interval. We used the Tmax for analyses because of its stronger correlation with 204 the tree-ring record than with mean or minimum monthly temperatures. Wilson et al. (2017), in 205 their investigation of BI and RW series for mountain hemlock (using dBi), used mean monthly 206 temperatures from stations within $57^{\circ}-61^{\circ} \mathrm{N}, 134^{\circ}-153^{\circ} \mathrm{W}$, a broader region than our study, as 207 they analyzed multiple sites across a larger swath of the GOA. Although we obtained marginally 208 better results with maximum temperatures from this larger area, we chose to use a more 209 restricted area to better represent the region surrounding our sampling sites (Fig. 1). It is difficult 210 to assess the temperatures at the tree-ring sites relative to the meteorological stations and we 211 have no records of frost frequency at the individual sites. January (coldest month) Tmax values 
212 correlated at $0.95(\mathrm{~N}=96$ years) with temperatures at the Juneau station, near sea level south of

213 the study sites. However, the Tmax series is about $6^{\circ} \mathrm{C}$ colder than Juneau values, which may be

214 closer to the actual temperatures at the sites up to 480 meters in elevation.

215 To assess the temporal stability of the tree-ring series and Tmax we performed running

216 correlations between series using 15-year and 31-year windows. To account for autocorrelation

217 in the series we examined correlations between the first differenced data. We also compared

218 running correlations between the yellow-cedar latewood BI series (YCLBi) and a published tree-

219 ring based temperature reconstructions for the Gulf of Alaska (Wiles et al., 2014).

\section{3. Results}

222 The RW series at the three sites span a common period of CE 1400-1975 (prior to a divergence

223 of the LBi and RW series; Fig. 2a) and correlate between 0.65 and 0.81 with one another,

224 whereas the three sites for $\mathrm{LBi}$, correlations ranged from 0.39 to 0.53 (Table 2). The lower

225 correlation among the LBi series is consistent with our observations of mountain hemlock BI

226 along the GOA (Wilson et al, 2017), white spruce (Picea glauca (Moench) Voss) in the Yukon

227 (Wilson et al., in press), and scots pine (Pinus sylevestris L.) in Scotland (Ryvdal et al., 2014).

228 As is found here, these cited studies found a weaker common signal among BI series relative to

229 the RW, but a stronger climate signal in the BI than the RW. This paradox is not well understood 230 at the present time.

231 The final chronologies were created by combining the three individual sites into one RW

232 and one YCLBi regional series (Fig.2). The two series correlate with one another at 0.49 for the

233 period of overlap between 1400 and 1975 CE (Fig. 2a) after which they diverge. The RW and

234 YCLBi series match well with the exception of intervals in the mid 1500s, early to mid 1600s 
235 and after about CE 1970 (Fig. 2a). About 1975, the YCLBi record strongly decreases and the

236 RW series declines marginally and then generally increases through recent decades (Fig. 2; Table

237 3). Comparisons of RW and YCLBi series with Tmax from the CRU gridded dataset were made

238 for the "dendroclimatic year" that consists of March through December of the previous year of

239 growth and January through October of the year of growth (Fig. 3). For the YCLBi, the strongest

240 correlations (Pearson two-tailed) were with mean January through August (J-A) maximum

241 temperatures at 0.64 for $1901-1975(\mathrm{p}<0.00001)$, with a $1^{\text {st }}$ differenced correlation of $0.71(1902-$

242 1975; $<<0.00001 ;$ Fig. 3a). After 1975, there is a marked decrease in correlation and loss of

243 significance $(\mathrm{r}=0.21 \mathrm{p}>0.34)$ for the non-transformed series with a $1^{\text {st }}$ differenced correlation of

2440.33 ( $\mathrm{p}=0.14$, also not significant) for the 1976-1999 interval (Figs. 3b, 4a). For the 2000-2014

245 interval, the correlation increases to $0.71(\mathrm{p}=0.004)$ with an increase in the $1^{\text {st }}$ differenced data

246 correlation to 0.64 ( $\mathrm{p}=0.01$ ) (Fig. 4b) comparable to the pre-1975 relationship (Fig. 3c). RW was

247 positively correlated with temperature $(\mathrm{J}-\mathrm{A})$ prior to $1976(\mathrm{r}=0.30, \mathrm{p}<0.01)$ and after that time

248 correlations with maximum temperatures are not significant (Fig. 3a).

249 A principal result of our analyses is that the YCLBi is more sensitive to, and thus

250 provides a much stronger proxy for maximum temperatures (January-August average) than RW.

251 Furthermore, decadal variations in climate along the GOA as inferred from the YCLBi record

252 appear nonstationary, especially during the climatic shift in the mid to late 1970s. This noted so-

253 called 1976/77 regime shift in the North Pacific is well-documented in terms of the physical and

254 biological changes that occurred in the region (Ebbesmeyer et al., 1991; Mantua et al., 1997;

255 Trenberth and Hurrell, 1994; Newman et al., 2016). In southeast Alaska, this shift brought

256 warmer temperatures with less snow but higher precipitation as rain (Wendler et al., 2017). The

257 loss of sensitivity in YCLBi to maximum temperature after this shift is consistent with the 
258 hypothesis that warming decreases snowpack, thus potentially exposing the shallow roots to frost

259 (the decline hypothesis). This dropoff in correlation also corresponds with a peak of cedar

260 mortality in the late 1970s to the early 1980s elsewhere in southeast Alaska (Hennon et al., 2016;

261 Hennon and Shaw, 1994). The apparent recovery in climate signal after the 1999 negative shift

262 in climate discussed in Ding et al. (2013), analyzed in McAfee (2016) and reported by Wills et

263 al. (2018) is marked here by a strengthening in correlation with Tmax and is also consistent with

264 the decline hypothesis. A recovery of climate sensitivity with respect to Tmax after 1999 appears

265 to be strongest in the year-to-year, high frequency response (differenced data; Fig. 4b). It also

266 appears that the lower frequency (decadal) response is also in recovery, although this finding is

267 preliminary (Fig. 4).

268

269 4. Discussion

270 To explore these changes in climate response further we compared our new YCLBi series

271 with a published climate reconstructions based on ring widths (GOARW; Wiles et al., 2014).

272 This record is derived from coastal mountain hemlock sites along the Gulf of Alaska. The

273 GOARW record sustains a strong positive relationship with mean temperature throughout the

274 post 1976/77 regime shift (a so-called "divergence-free" reconstruction; Wiles et al., 2014). This

275 "divergence-free" series was constructed to minimize the effect of the changing climate response

276 of mountain hemlock RW recognized at some elevations along the southern Alaskan coast

277 (Jarvis et al., 2013; Wiles et al., 2014). As discussed above, the YCLBi record correlates best

278 with maximum average (January-August) temperatures, which is similar to the response of the

279 GOARW series that has been used to reconstruct mean February-August temperatures (Wiles et

280 al., 2014). Thus, the two compare favorably (Fig. 5a), with the YCLBi record correlating with 
281 the GOARW (Wiles et al., 2014; Fig. 5a) series at $0.43(\mathrm{p}<0.00001)$ for the interval 1400-1975

282 (Fig. 5a). The 31-year running correlations of these two series show generally good agreement 283 except for the 1976-1999 interval (Fig. 5b). Correlations are strongest for the 1670-1930 period 284 (Fig. 5b). Subsequently, there is a dramatic drop after 1975 (not significant $(r=-0.19)$ for the 285 1976-1999 interval) and then a marked recovery in correlation between the two series after 1999 $286(\mathrm{r}=0.70(\mathrm{p}<0.05)$; Table 3; Fig. 5b), which persists to the present (2014). First differenced 287 transformations (detrended) agree better for that interval (1976-1999); however, they also do not 288 match well in the mid 1600s (Fig. 5b).

289 A similar comparison was made with the YCLBi and the Gulf of Alaska dBi (GOAdBi) 290 series of Wilson et al. (2017; Table 3). Similar to the GOARW the GOAdBi series shows no 291 signs of divergence. Many of the same tree-ring sites included in the GOAdBi series are also 292 incorporated into the GOARW reconstruction, however GOAdBi also include dBi series that 293 responded strongly to June-September mean temperatures. The comparison of the pre-1976, 294 1976/99 and 2000/14 intervals yielded consistent but somewhat stronger correlations (Table 3) as 295 those of the YCLBi and GOARW comparisons. The two series agree especially well for the $2962000 / 14$ interval with a correlation of 0.80 for the non-transformed series and 0.82 for the first 297 differenced series, both highly significant $(\mathrm{p}<0.01$; Table 3$)$.

298 Taken together, the changing climate response and comparison of the YCLBi series with 299 the Tmax series (Fig.4), and the GOARW (Fig.5) and GOAdBi (Table 3) reconstructions suggest 300 that yellow-cedar may have crossed a temperature threshold about 1976 (Fig. 3), which then 301 altered the interannual climate response of the species for about 20 years. The negative trend in 302 the YCLBi series for this interval may now be in recovery as suggested by the strong positive 303 response to Tmax in recent decades. As noted, the late 1970s and early 1980s also represent a 
304 peak wave of recent yellow-cedar mortality in southeast Alaska (Hennon et al., 2016). The 1976

305 threshold shift may have led to multiple years of successive injury altering climate sensitivity,

306 although mortality has not been observed at our sites. Furthermore, in the course of the analyses

307 we did not observe any evidence of injury in the wood such as traumatic resin ducts. Importantly,

308 yellow-cedar freezing injury is classified as a "forest decline" because it often takes multiple

309 freezing events and years of injury before eventual mortality.

310 The correspondence of YCLBi change with the mid-1970s regime shift from a

311 dominantly negative to dominantly positive PDO caused strong warming in coastal regions in

312 southeastern Alaska and thus a reduction in snowpack is consistent with the decline hypothesis.

313 This possible threshold crossing is likely associated with the physiological limits of yellow-

314 cedar, wherein its sensitivity to temperature becomes decoupled (D’Arrigo et al. 2004; Ohse et

315 al. 2012). Wang et al. (2014) documented an analogous divergence between temperature and RW

316 in five species from southeastern China, also in response to the 1976-77 regime shift. To our

317 knowledge, the Juneau YCLBi results presented here are the first tree ring studies to suggest the

318 effects of this relatively recent phenomenon on yellow-cedar populations in southeastern Alaska.

319 The favorable comparisons of the YCLBi series with the GOARW tree-ring series (Fig.

320 5a) prior to 1976 and then again after 1999 also suggest that the changes documented in yellow-

321 cedar in recent decades are unprecedented at least since CE 1400 (Fig. 5a; Table 3). Our results

322 indicate, therefore, that decadal shifts in addition to century-scale warming should be considered

323 when assessing the climate response of yellow-cedar. The strong coherence between the series

324 additionally, suggests that the conditions forcing the divergence after 1976 were likely not

325 experienced since at least 1400 CE. Furthermore, with the caveat that in some of our samples we

326 detected a change in color in the heartwood-sapwood transition, the temporary loss of climate 
327 signal (between 1976-1998) suggests that the divergence here at least to some degree has 328 recovered.

329 Previous work has focused on the secular warming since the Little Ice Age as a dominant 330 driver in cedar decline and this is clearly consistent with the data. However, decadal shifts 331 superimposed on this warming can also be instrumental in changing growing conditions and 332 subsequent stresses. For southeast Alaska, a $\sim 1.1^{\circ} \mathrm{C}$ warming during the period 1976-1999

333 relative to the previous 1951-1975 interval (Hartmann and Wendler, 2005) occurred. At the time 334 of this shift, the amount of annual snowfall decreased by $36 \%$ while overall total precipitation 335 increased by $7 \%$ with an approximately $7 \%$ increase in rain during the late summer to early fall 336 months (JAS) (Hartmann and Wendler 2005). This higher percentage of precipitation falling as 337 rain after the mid-1970s shift, forced by the increased warming, may also have influenced the 338 simultaneous marked shift in YCLBi.

339 Sullivan et al. (2017) noted a summer temperature driven response to a more moisture340 limited signal in Alaskan white spruce (Picea glauca) and, similar to our work, did not detect a 341 widespread decrease in radial growth (RW). These results from interior Alaska are in contrast to 342 earlier work at some interior sites, (ie., Barber et al., 2000; Juday et al., 2003; Juday and Alix, 343 2012; D'Arrigo et al., 2008) which identified a recent reduction in radial growth likely due to 344 moisture stress. Additionally, for white spruce in the interior of Alaska, Ohse et al. (2012) point 345 out that growth is further complicated by regional gradients in climate and site-specific 346 attributes, as well as Pacific decadal climate shifts, which also have been implicated for these 347 transitions. Finally, Wright et al. (2018) identified the role of stand dynamics in southwestern 348 Alaska can drive varying degrees of temperature stress responses. 
Blue-intensity parameters measured in yellow-cedar could complement such studies of

350 divergent tree growth and warming temperatures in northern forests, which have been primarily

351 based on ring-widths (D'Arrigo et al., 2008). Here the YCLBi measurements show a change,

352 whereas the RW do not, suggesting that blue intensity, at least for yellow cedar, may experience

353 divergent phenomena. Thus, when the limiting factors on growth at a location change, it may

354 result in distinct challenges for using blue intensity from yellow-cedar in dendroclimatology. It is

355 possible that a band-pass approach could be performed with RW providing the low frequency

356 signal with the BI record providing the higher frequency signal (Wilson et al., 2014). However,

357 the challenge remains that the climate sensitivity of the RW is not as strong as the YCLBi record,

358 although the multi-decadal to century scale variability appears to be relatively coherent (Fig. 2).

359 Requiring further investigation is the divergence in the BI record that may be influenced

360 by heartwood-sapwood color differences even though we did not observe a strong visual color

361 change in many of the cores. Such factors warrant more detailed evaluation to ensure that BI data

362 are able to adequately capture climatic variability through the last several decades. Whereas this

363 needs to be investigated more fully for yellow-cedar, the coincidence of loss of signal (non-

364 significant correlations) at times of known shifts in climate (1976/77 and 1999) supports a

365 climate-driven response of the tree growth. Further work could include investigating other

366 chemical treatments of the wood prior to analysis (Rydval et al., 2014). Delta BI (dBi) proposed

367 to ameliorate the heartwood/sapwood transition also shows a strong divergence (not shown) but

$368 \mathrm{dBi}$ is much less sensitive to temperature variability in this study perhaps because of the strong

369 intercorrelation between the LWBi and EWBi series, and so is not helpful here. In contrast, for

370 the GOA mountain hemlock dBi seems to be a more climatically sensitive parameter than LWBi

371 (Wilson et al., 2017). 
Our YCLBi series is climatically sensitive to January through August maximum average

373 temperatures a broader climate window than the June-September sensitive GOAdBi study by

374 Wilson et al. (2019). We hypothesize that the broader climate window for the YCLBi record

375 compared with the more restricted summer signal found in Wilson et al (2017) may be due to the

376 ecophysiological tendency of yellow-cedar to deharden earlier in the spring, thus responding

377 favorably to winter/spring temperatures. This early dehardening may allow yellow cedar to gain

378 a competitive advantage with respect to nutrient uptake (D'Amore et al., 2009) relative to other

379 conifer species and thus yellow-cedar respond to late winter/spring temperatures as well as

380 summer.

Finally, although the three sites in this investigation have not shown indications of

382 decline at the stand level or a marked decrease in radial growth (RW), they appear to have been

383 impacted by changes in climate in the mid to late 1970 s, behaving similarly to stands that have

384 experienced extensive mortality (Beier et al., 2008). Since about 1999, these populations

385 recovered their climate sensitivity suggesting some level of resilience. This is consistent with the

386 concept that this population is "on the edge" of climatic vulnerability (Buma, 2018). Thus, it may

387 be that at some of the locations in the Juneau area, yellow-cedar sites remain healthy forests.

388 However, since they are near the leading edge of the decline and outside of the "historical

389 decline," a slight warming in the region could push these trees closer toward conditions of

390 potential mortality as recognized farther south in coastal Alaska.

As Buma (2018) points out, across the range of yellow-cedar, if the rate of warming is

392 great enough to ameliorate the occurrence of frost, then the warming and loss of snowpack may

393 not influence cedar growth. Although the roots are vulnerable, frosts are less likely to occur in a

394 rapidly warming climate. A drop toward nonsignificant correlations in both the non-transformed 
395 and first differenced series between 1976 and 1999 is consistent with stress-related changes,

396 perhaps related to warming temperatures and its interactions with snowpack and frost.

397 Furthermore, the secular increase as well as the decadal changes in the North Pacific emphasized

398 here will drive and modulate the tree response to climate.

Clearly, decadal-scale variability needs to be considered in the context of forest health. It

400 is difficult to separate the effect of secular warming and the decadal shifts from one another and

401 it is likely that they have worked synergistically to cause the decoupling of tree growth and

402 maximum temperature. Hennon et al. (2016) point out that although the yellow-cedar competes

403 well on saturated soils relative to other species, trees rooted in saturated soils tend to have more

404 shallow rootlets making them more vulnerable to freezing damage. The species' preference and

405 its ability to out-compete other tree species on wetter soils can increase their vulnerability to

406 freezing if the insulating layer of snow disappears so that shallow roots can freeze. Even though

407 the primary driver in the decline remains temperature, increased precipitation may also

408 exacerbate the tree stress related to warmer temperatures, loss of snow pack, and the detrimental

409 impact of frosts on root systems. These factors need to be explored more fully.

410 Our results suggest that with further work YCLBi records could be used to reconstruct

411 past climate. Melting glaciers across the GOA continue to reveal ancient forests, and in at least

412 one case, have exposed sub-fossil wood that includes yellow-cedar (Gaglioti et al., unpublished

413 data). This presents the emerging possibility of extending these cedar series further back in time.

414 As in the case for mountain hemlock (Wilson et al., 2017), blue intensity tree-ring series in

415 yellow-cedar show promise to improve temperature reconstructions for the GOA and perhaps in

416 the future entering into multi-species climate reconstructions. 


\section{Conclusions}

This analysis of yellow-cedar response to climate is the first to examine the latewood

420 blue intensity parameter. Previous work with ring-widths from yellow cedar of southeast Alaska,

421 although valuable in examining changing climate response, have been limited with respect to

422 reconstructing past climate. Our well-replicated YCLBi series has a strong temperature response

423 until the mid-1970s equal to or greater than many published ring-width series from the

424 traditionally used mountain hemlock from the region.

425 The trends in the observational climate records and in the YCLBi data suggest changes in 426 tree physiology around the mid-1970s shift in the PDO that may have been detrimental to tree

427 growth but do not necessarily appear to be affecting bioproductivity as inferred from ring-widths.

428 The presumed recovery in temperature sensitivity in YCLBi after a shift to a cooler regime in

429 1998/99 (Wills et al., 2018) is further evidence of a response to decadal climate change, although

430 additional years for comparison in the coming decades may strengthen or refute this observation.

431 The climate sensitivity of this economically, ecologically and culturally important species should

432 be coupled with the existing knowledge of past migrations and the mechanisms of decline when

433 anticipating its future range (Krapek et al., 2017), especially in the face of unprecedented

434 warming.

435 Further study of the impact of decadal shifts and secular warming in yellow-cedar across

436 its range, together with monitoring could help anticipate the risks that these sites may experience

437 in the future. This work emphasizes the findings of previous studies on the ecology of yellow-

438 cedar (Krapek and Buma, 2017), supporting the observation that this species has not responded

439 linearly to secular warming. 


\section{Acknowledgements:}

442 This work was supported by the National Science Foundation's Paleoclimatic Perspectives on 443 Climatic Change (P2C2) Program grant nos. AGS 1159430, AGS 1502186, AGS 1502150, and 444 PLR 15-04134 and by the Keck Geology Consortium funded by The National Science 445 Foundation under Grant No. (NSF-REU \#1358987). We are also grateful to the National Forest 446 Service. Lamont-Doherty Earth Observatory Contribution \#8345.

\section{References}

449 Barber, V.A., Juday, G.P., and, Finney, B.P. 2000. Reduced growth of Alaskan white spruce in 450 the twentieth century from temperature-induced drought stress. Nature 405: 668-673.

452 Barclay, D.J., Wiles, G.C., and, Calkin, P.E. 1999. A 1119-year tree-ring width chronology from 453 western Prince William Sound, southern Alaska. The Holocene 9: 79-84.

Barrett, T.M., and Pattison, R.R. 2017. No evidence of recent (1995-2013) decrease of yellow456 cedar in Alaska. Can. Jour. of For. Res. 47: 97-105.

458 Beier, C.M., Sink, S.E., Hennon, P.E., D’Amore, D.V., and, Juday, G.P. 2008. Twentieth459 century warming and the dendroclimatology of declining yellow-cedar forests in southeastern 460 Alaska Can. Jour. of For. Res. 38: 1319-1334.

462 Bidlack, A., Bisbing, S., Buma, B., D’Amore, D., Hennon, P., Heutte, T., Krapek, J., Mulvey, R., 463 and, Oakes, L. 2017. Alternative interpretation and scale-based context for "No evidence of 
464

465 of For. Res. 47: 1145-1151.

466

467 Björklund, J., Gunnarson, B.E., Seftigen, K., Esper, J., and, Linderholm, H.W. 2014. Blue

468

469

470

471 Björklund, J., Gunnarson, B.E., Seftigen, K., Zhang, P., and, Linderholm, H.W. 2015. Using

472 adjusted blue intensity data to attain high-quality summer temperature information: A case study

473 from Central Scandinavia. The Holocene 25: 547-556.

475 Boulton, C.A., and, Lenton, T.M. 2015. Slowing down of North Pacific climate variability and

476 its implications for abrupt ecosystem change. Proc. Nat. Acad. of Sci. 112: 11496-11501.

477 Buckley, B., Hansen, K.G., Griffin, K.L., Schmiege, S., Oelkers, R., D’Arrigo, R.D., Stahle,

478 D.K., Davi, N., Nguyen, T., Le, C.N., and, Wilson, R.J.S. 2018. Blue intensity from a tropical

479 conifer's annual rings for climate reconstruction: An ecophysiological perspective.

480 Dendrochronologia 50: 10-22.

482 Buma, B. 2018. Transitional climate mortality: slower warming may result in increased climate483 induced mortality in some systems. Ecosphere 9: e02170.

485 Buma, B., Hennon, P.E., Harrington, C.A. Popkin, J.R., Lamb, M.S., Oakes, L.E., Saunders, S., 486 and, Zeglen, S. 2017. Emerging climate-driven disturbance processes: widespread mortality 
487 associated with snow-to-rain transitions across $10^{\circ}$ of latitude and half the range of a climate-

488 threatened conifer. Global Change Biology 23: 2903-2914.

490 Campbell, R., McCarroll, D., Loader, N.J., Grudd, Häkan, Robertson, I., and, Jalkanen, R. 2007.

491 Blue intensity in Pinus sylvestris tree-rings: developing a new palaeoclimate proxy. The

492 Holocene 17: 821-828.

493

494 Charlton, J., Cruz, A., Lummus, M., Loadholt, K., Messerich, C., Wiles, G., Buma, B., and, 495 Krapek, J. 2017. Yellow cedar growth response to decadal climatic shifts at Cedar Lake, Juneau, 496 Alaska. Geol. Soc. Am. Abst. Progr. 49, Seattle, Washington, USA, 22-25 October 2017.

498 Cohen, W.B., Yang, Z., Stehman, S.V., Schroeder, T.A., Bell, D.B., Masek, J.G., Huang, C., 499 and, Meigs, G.W. 2016. Forest disturbance across the conterminous United States from 1985500 2012: The emerging dominance of forest decline. For. Ecol. and Management 360: 242-252.

502 Cook, E.R. 1985. A Time Series Analysis Approach to Tree-Ring Standardization. PhD Thesis, 503 University of Arizona, Tucson, USA.

D’Amore, D.V., and, Hennon, P.E. 2006. Evaluation of soil saturation, soil chemistry, and early

506 spring soil and air temperatures as risk factors in yellow-cedar decline. Glob. Chan. Biol. 12:

$507 \quad 524-545$.

508

509 D’Amore, D.V., Hennon, P.E., Schaberg, P.G. and, Hawley, G. J. 2009. The adaptation to 
510 exploit nitrate in surface soils predisposes yellow-cedar to climate change-induced decline and 511 enhances the survival of red cedar. For. Ecol. and Management 258: 2261-68.

513 D’Arrigo, R., Kaufmann, R.K., Davi, N., Jacoby, G.C., Laskowski, C., Myneni, R.B., and,

514 Cherubini, P. 2004. Thresholds for warming-induced growth decline at elevational tree line in 515 the Yukon Territory, Canada. Glob. Biogeochem. Cycles 18: GB3021.

517 D'Arrigo, R., Villalba, R., and, Wiles, G. 2001. Tree-ring estimates of Pacific decadal climate 518 variability. Clim. Dyn. 18: 219-224.

520 D’Arrigo, R., Wilson, R., Liepert, B., and, Charubini, P. 2008. On the 'Divergence Problem' in 521 Northern Forests: A review of the tree-ring evidence and possible causes. Glob. Planet. Chan. 522 60: 289-305.

524 Ding, H., Greatbatch, R. J., Latrif, M., Park, W., and Gerdes, R., 2013, Hindcast of the 1976/77 525 and 1998/99 climate shifts in the Pacific: J. Climate. Doi 10.1175/JCLI-12-00626.1.

527 Dolgova, E. 2016. June-September temperature reconstruction in the Northern Caucasus based 528 on blue intensity data. Dendrochronologia 39: 17-23.

530 Ebbesmeyer, C.C., Cayan, D.R., Mclain, D.R., Nichols, F.H., Peterson, D.H., and, Redmond, 531 K.T. 1991. 1976 step in the Pacific climate: forty environmental changes between 1968-1975 
532 and 1977-1984. In: Proceedings of the 7th Annual Climate (PACLIM) Workshop (ed by

533 Betancourt JL and Tharp VL), April 1990, pp. 115-126. California Department of Water

534 Resources, Interagency Ecological Studies Program Technical Report 26.

535

536 Fuentes, M., R. Salo, J. Björklund, K. Seftigen, P. Zhang, B. Gunnarson, J. Aravena and H.

537 Linderholm. 2018. A 970-year-long summer temperature reconstruction from Rogen, west-

538 central Sweden, based on blue intensity from tree rings. The Holocene 28: 254-266.

540 Gaglioti, B.V., Mann, D.H., Williams, A.P., Wiles, G.C., and, Jones, B. accepted 2019, Sudden

541 shifts in wintertime Aleutian Low variability revealed in a 550-year record of storm-damaged

542 trees from Southeast Alaska. Journal of Geophysical Research - Biosciences.

544 Grissino-Mayer, H.D. 2001. Evaluating crossdating accuracy: A manual and tutorial for the 545 computer program COFECHA. Tree-Ring Research 57: 205-221.

547 Harris, I., Jones, P.D., Osborn, T.J., and, Lister, D. 2014. Updated high-resolution grids of 548 monthly climatic observations - the CRU TS3. 10 Dataset. Intern. Jour. of Clim. 34: 623-642.

550 Hartmann, B. and, Wendler, G. 2005. The significance of the 1976 Pacific climate shift in the 551 climatology of Alaska. Jour. of Clim. 18: 4824-4839. 
554 development of yellow-cedar decline in southeast Alaska? For. Path. 24: 399-418.

555

556 Hennon, P.E., D’Amore, D.V., Schaberg, P.G., Wittwer, D.T., and, Shanley, C.S. 2012. Shifting

557 climate, altered niche, and a dynamic conservation strategy for yellow-cedar in the North Pacific 558 coastal rainforest. BioScience 62: 147-158.

559

560 Hennon, P.E., D’Amore, D., Wittwer, D., Johnson, A., Schaberg, P., Hawley, G., Beier, C., and,

561 Sink, G. 2006. Climate warming, reduced snow, and freezing injury could explain the demise of 562 yellow-cedar in southeast Alaska, USA. World Res. Rev. 18: 227-250.

564 Hennon, P.E., McKenzie, C.M., D’Amore, D., Wittwer, D.T., Mulvey, R.L., Lamb, M.S., Bile, 565 F.E. and Cronn, R.C., and, Juday, G. 2016. A climate adaptation strategy for conservation and 566 management of yellow-cedar in Alaska. Pacific Northwest Research Station General Technical 567 Report no. 917. Portland, Oregon, USA: US Department of Agriculture, Forest Service.

569 Hennon, P.E., Shaw, C.G., and, Hansen, E.M. 1990. Dating decline and mortality of 570 Chamaecyparis nootkatensis in southeast Alaska. For. Sci. 36: 502-515.

572 Holmes, R. 1983. Computer-assisted quality control in tree-ring dating and measurement. Tree573 Ring Bull. 44: 69-74.

575 Jarvis, S. K., Wiles, G.C., Appleton, S.N., D’Arrigo, R.D., and, Lawson, D.E. 2013. A warming576 induced biome shift detected in tree growth of Mountain Hemlock (Tsuga mertensiana (Bong.) 
577 Carrière) along the Gulf of Alaska. Arct., Ant. and Alp. Res. 45, DOI 10.1657/1938-4246-45.2.

578

579 Juday G. P., Barber V., Rupp S., Zasada, J. and Wilmking, M. 2003. Climate Variability and

580 Ecosystem Response at Long-Term Ecological Research Sites ed. D Greenland et al (New York:

581 Oxford University Press) pp 226-50

582 Juday, G.P., and Alix, C. 2012. Consistent negative temperature sensitivity and positive

583 influence of precipitation on growth of floodplain Picea glauca in interior Alaska. Can. J. For.

584 Res. 42: 561-573. doi:10.1139/x2012-008.

585 Kaczka, R., J., Spyt, B., Janecka, K., Beil, I., Büntgen,U., Scharnweberb, T., Nievergeltd, D.,

586 and, Wilmking, M. 2018. Different maximum latewood density and blue intensity measurements

587 techniques reveal similar results. Dendrochronologia, 49: 94-101,

588 https://doi.org/10.1016/j.dendro.2018.03.005.

589

590 Krapek, J., and Buma, B. 2015. Yellow-cedar: climate change and natural history at odds. Front.

591 in Ecol. and Envir. 13: 280-281.

592

593 Krapek, J., and, Buma, B. 2017. Persistence following punctuated range extension: limited

594 dispersal of migrating tree despite habitat ahead of its range. Jour. of Ecol. 106: 911-924.

596 Krapek, J., Hennon, P.E., D’Amore, D.V., and, Buma, B. 2017. Despite available habitat at 597 range edge, yellow-cedar migration is punctuated with a past pulse tied to colder conditions.

598 Diversity and Distributions 23: 1381-1392. 
600 Larsson, L-Å. 2016. CDendro \& CooRecorder program package for tree ring measurements and

601 crossdating of the data, version 8.1.1. Available at: http://www.cybis.se/forfun/dendro.

602

603 Manion, P.D., and, Lachance, D., 1992. Forest decline concepts. St. Paul: American Phyto-

604 pathological Society Press.

605

606 Mantua, N.J., Hare, S.R., Zhang, Y., Wallace, J.M., and, Francis, R.C. 1997. A Pacific

607 Interdecadal climate oscillation with impacts on salmon production. Bull. of the Am. Met. Soc.

608 78: 1069-1079.

609

610 Marcinkowski, K., Peterson, D.L. and Ettl, G.J. 2014. Nonstationary temporal response of

611 mountain hemlock growth to climatic variability in the North Cascade Range, Washington, USA.

612 Can. J. For. Res. 45: 676-688.

613

614 McAfee, S.A. 2014. Consistency and the lack thereof in Pacific Decadal impacts on North

615 American winter climate. J. Clim. 27: 7410- 7431.

616

617 McAfee, S.A. 2016. Uncertainty in Pacific decadal oscillation indices does not contribute to 618 teleconnection instability. Int. J. Climatology 37: https://doi.org/10.1002/joc.4918. 
620 McCarroll, D., Pettigrew, E., Luckman, A., Guibal., F., and, Edouard, J.L. 2002. Blue reflectance

621 provides a surrogate for latewood density of high-latitude pine tree rings. Arct., Ant., and Alp.

622 Res. 34: 450-453.

623

624 Melvin, T.M., and, Briffa, K.R. 2008. "Signal-free" approach to dendroclimatic standardisation.

625 Dendrochronologia 26: 71-86.

626

627 Melvin, T.M., and, Briffa, K.R. 2014. CRUST: Software for the implementation of Regional

628 Chronology Standardisation: Part 2. Further RCS options and recommendations.

629 Dendrochronologia 32: 343-356.

630

631 Melvin, T.M., Briffa K.R., Nicolussi, K., and, Grabner, M. 2007. Time-varying-response

632 smoothing. Dendrochronologia 25: 65- 69.

633

634 Newman, M., Alexander, M.A., Ault, T.R., Cobb, K.M., Deser, C., Di Lorenzo, E., Mantua, 635 N., Miller, A.J., Minober, S., Nakamurai,H., Schneider, N., Vimont, D.J., Phillips, A.S., Scott, 636 J.D., and, Smith, C.A. 2016. The Pacific decadal oscillation, revisited. Jour. of Clim. 29: 43996374427.

638

639 Oakes, L.E., 2018, In search of the canary tree. Hachette Book Group. 272 p. 
641 Oakes, L.E., Hennon, P.E., Ardoin, N.M., D’Amore, D., Feruson, A.J., Steel, E.A., Wittwer,

642 D.T., and Lambin, E.F. 2015. Conservation in a social-ecological system experiencing climate-

643 induced tree mortality. Biol. Cons. 192: 276- 285.

644

645 Oakes, L.E., Hennon, P.E., O’Hara, K.L., O’Hara, K.L., and, Dirzo, R. 2014. Long-term

646 vegetation changes in a temperate forest impacted by climate change. Ecosphere 5:1-28.

648 Ohse, B., Jansen, F., and, Wilmking, M. 2012. Do limiting factors at Alaskan treelines shift with

649 climatic regimes? Envir. Res. Lett. 7: 1-12.

650

651 Overland, J., Rodionov, S., Minobe. S., and Bond, N., 2008. North Pacific regime shifts:

652 Definitions, issues and recent transitions: Progress in Oeanography, 77: 92-102.

654 Peterson, T.C., and, Vose, R.S. 1997. An overview of the Global Historical Climatology

655 Network temperature database. Bull. of the Am. Met. Soc. 78: 2837-2849.

656 Rydval, M., Larsson, L-Å., McGlynn, L., Gunnarson, B.E., Loader, N.J., Young, G.H.F., and, 657 Wilson. R. 2014. Blue intensity for dendroclimatology: Should we have the blues? Experiments 658 from Scotland. Dendrochronologia 32: 191-204.

660 Rydval, M., Loader, N.J., Gunnarson, B.E. Druckenbroad, D.L., Linderholm, H.W., Moreton, 661 S.G., Wood, C.V., and Wilson, R. 2017. Reconstructing 800 years of summer temperatures in 662 Scotland from tree rings. Clim. Dyn. 49: 29-51. 
664 Schaberg, P.G., D’Amore, D.V., Hennon, P.E., Halman, J.M., Hawley, G.J.,. 2011. Do limited 665 cold tolerance and shallow depth of roots contribute to yellow-cedar decline? For. Ecol. and 666 Manage. 262: 2142-2150.

668 Schaberg, P.G., Hennon, P.E., D’Amore, D., Hennon, P.E., Halman, J.M., and, Hawley, G.J. 669 2008. Influence of simulated snow cover on the cold tolerance and freezing injury of yellow670 cedar seedlings. Glob. Chan. Biol. 14: 1-12.

672 Sullivan, P.F., Pattison, R.R., Brownlee, A.H., Cahoon, S.M.P., and, Hollingsworth, T.N. 2017.

673 Limited evidence of declining growth among moisture-limited black and white spruce in interior 674 Alaska. Scientific Reports 7: 15344.

676 Trenberth, K.E., and, Hurrell, J.W. 1994. Decadal atmosphere-ocean variations in the Pacific.

677 Clim. Dyn. 9: 303-319.

679 Trouet, V., and, Van Oldenborgh, G.J. 2013. KNMI Climate Explorer: A web-based research 680 tool for high-resolution paleoclimatology. Tree-Ring Res. 69: 3-13.

682 Wang. X., Li, Z., and, Ma, K. 2014. Decreased sensitivity of tree growth to temperature in 683 southeast China after the 1976/'77 regime shift in Pacific climate. Sains Malaysiana 43: 9-19.

685 Wendler, G., Gordon, T., and, Stuefer, M. 2017. On the precipitation and precipitation change in 
688 Wigley, T.M., Briffa, K.R., and, Jones, P.D. 1984. On the average value of correlated time 689 series, with applications in dendroclimatology and hydrometeorology. Jour. of Clim. and Appl.

690 Meteor. 23: 201-213.

692 Wiles, G.C., D’Arrigo, R.D., Barclay, D, Javis, S., Appleton, S., Wiesenberg, N., and Lawson, 693 D. 2014. Surface air temperature variability reconstructed with tree rings for the Gulf of Alaska 694 over the past 1200 years. The Holocene 24: 198-208.

695

696 Wiles, G.C., Mennett, C.R., Jarvis, S.K., D’Arrigo, R.D., Wiesenberg, N., and, Lawson, D. 2012.

697 Tree-ring investigations into changing climatic responses of Yellow-Cedar, Glacier Bay, Alaska.

698 Can. J. For. Res. 42: 814-819.

699

700 Wills, R.C., Schneider, T., Wallace, J.M., Battisti, D.S., and Hartman, D. L. 2018. Disentangling 701 global warming, multidecadal variability, and el Nino in Pacific temperatures. Geophys. Res.

702 Lett. 45: https://doi.org/10.1002/2017GL076327.

703

704 Wilson, R., Anchukaitis, K., Andreu Hayles, L., Cook, E., D’Arrigo, R., Davi, N., Haberbauer, 705 L., Krusic, P., Luckman, B., Morimoto, D., Oelkers, R., Wiles, G., and Wood, C., in press, 706 Improved dendroclimatic calibration using Blue Intensity for white spruce in the southern 707 Yukon. The Holocene. 
709 Wilson, R., Rao, R., Rydval, M., Wood, Larsson, L.A., and, Luckman, B.H. 2014. Blue intensity

710 for dendroclimatology: the BC blues: a case study from British Columbia Canada. The Holocene $71124: 1428-1438$.

712

713 Wilson, R., D’Arrigo, R., Andrew-Hayles. L., Oelkers, R., Wiles, G., Anchukaitis, K., and, Davi, 714 N. 2017. High-sensitivity warm-season climate signatures in a Gulf of Alaska Blue Light

715 Intensity tree-ring composite record. Clim. of the Past 13: 1851-1900, doi:10.5194/cp-2017-26.

717 Wilson, R., Wiles, G., D’Arrigo, R., and, Zweck, C. 2007. Cycles and shifts: 1300-years of

718 multidecadal temperature variability in the Gulf of Alaska. Clim. Dyn. 28: 425-440.

720 Wilmking, M., G. P. Juday, V. A. Barber, and H. S. Zald. 2004. Recent climate warming forces

721 contrasting growth responses of white spruce at treeline in Alaska through temperature

722 thresholds. Global Change Biology 10:1724-1736.

723

724 Wright, M., Sherriff, R.L., Miller, A.E., and Wilson, T., 2018, Stand basal area and temperature

725 interact to influence growth in white spruce in southwest Alaska. Ecosphere 9:

726 https://doi.org/10.1002/ecs2.2462. 
Table 1. Parameters of tree-ring sites shown in Figure 1.

\begin{tabular}{llllll}
\hline Site* & Lat./Long. & $\begin{array}{l}\text { Elev. } \\
(\mathrm{m})\end{array}$ & \# series/trees & Interval (CE) & $\begin{array}{l}\text { RBAR } \\
\text { LBi/RW }\end{array}$ \\
\hline BC & 58.6301, & 140 & $49 / 29$ & $1644-2014$ & $0.41 / 0.50$ \\
& -134.9304 & & & & \\
CL & 58.6655, & 110 & $70 / 41$ & $1611-2014$ & $0.41 / 0.46$ \\
& -134.9688 & & & & \\
EG & 58.4077, & 480 & $60 / 43$ & $1114-2014$ & $0.42 / 0.56$ \\
& -134.5243 & & & & \\
\hline
\end{tabular}

*BC - Bridget Cove; CL - Cedar Lake; EG - East Glacier (see Figure 1 for locations). RBAR is the mean correlation coefficient among tree-ring series.

Table 2. Correlations among ring-width $(R W)$ and latewood blue intensity (LBi) chronologies for the interval CE1750-1975 at individual tree-ring sites for non-transformed and first difference series (parens.).

\begin{tabular}{lllllll}
\hline Chron & $C L(R W)$ & $\underline{\mathrm{CL}(\mathrm{LBi})}$ & $B C(R W)$ & $\underline{\mathrm{BC}(\mathrm{LBi})}$ & $E G(R W)$ & $\underline{\mathrm{EG}(\mathrm{LBi})}$ \\
\hline$C L(R W)$ & ---- & $0.43(-0.03)$ & $\mathbf{0 . 8 1}(\mathbf{0 . 7 8})$ & $0.36(-0.04)$ & $\mathbf{0 . 6 5}(\mathbf{0 . 6 3})$ & $0.57(0.32)$ \\
$\mathrm{CL}(\mathrm{LBi})$ & & ---- & $0.37(0.05)$ & $\underline{0.53(0.47)}$ & $0.34(-0.02)$ & $\underline{0.39(0.28)}$ \\
$B C(R W)$ & & & ---- & $0.44(-0.02)$ & $\mathbf{0 . 7 6 ( 0 . 5 3 )}$ & $0.54(0.31)$ \\
$\mathrm{BC}(\mathrm{LBi})$ & & & & ---- & $0.42(-0.05)$ & $\underline{0.41(0.57)}$ \\
$\underline{E G(R W)}$ & & & & & --- & $0.51(0.19)$ \\
\hline
\end{tabular}

* BC - Bridget Cove; CL - Cedar Lake; EG - East Glacier (see Figure 1 for locations). Bold are comparisons between RW series and underlined are comparisons between LBi.

Table 3. Correlations among key tree-ring series relative to YCLBi and those used in climate reconstruction along the GOA. The first value is the non-transformed correlation and those in parentheses are $1^{\text {st }}$ differenced.

\begin{tabular}{llll}
\hline YCLBi_Cedar* & $1600-1975$ & $1976 / 99$ & $2000 / 14$ \\
\hline RW_Cedar & $\mathbf{0 . 5 3 ( 0 . 3 4 )}$ & $0.07(-0.41)$ & $0.42(0.15)$ \\
GOAdBi & $\mathbf{0 . 5 0}(0.04)$ & $0.18(0.56)$ & $\mathbf{0 . 8 0}(\mathbf{0 . 8 2})$ \\
GOARW & $\mathbf{0 . 4 8 ( 0 . 2 9 )}$ & $-0.19(0.16)$ & $\mathbf{0 . 7 0}(\mathbf{0 . 7 2})$ \\
\hline
\end{tabular}

*Bold correlations are significant $<0.01$ level. 


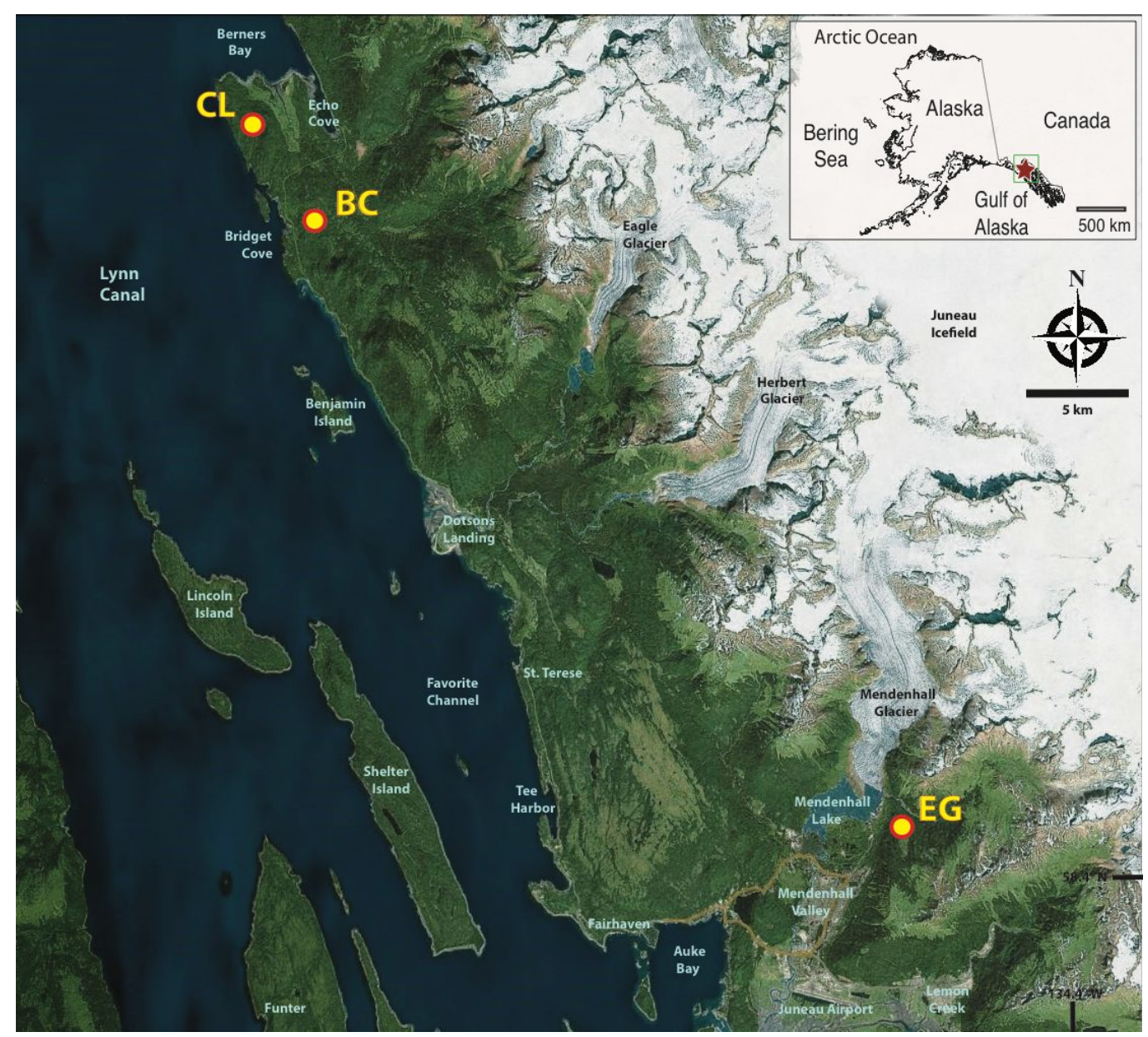

Fig. 1. Location of the three yellow-cedar sites used in the composite ring-width and latewood blue intensity (YCLBi) chronology $(\mathrm{CL}=$ Cedar Lake, $\mathrm{BC}=$ Bridget Cove, $\mathrm{EG}=$ East Glacier). The inset map shows the location of the Juneau area and the box includes the region over which the maximum temperature (Tmax) series were averaged. 

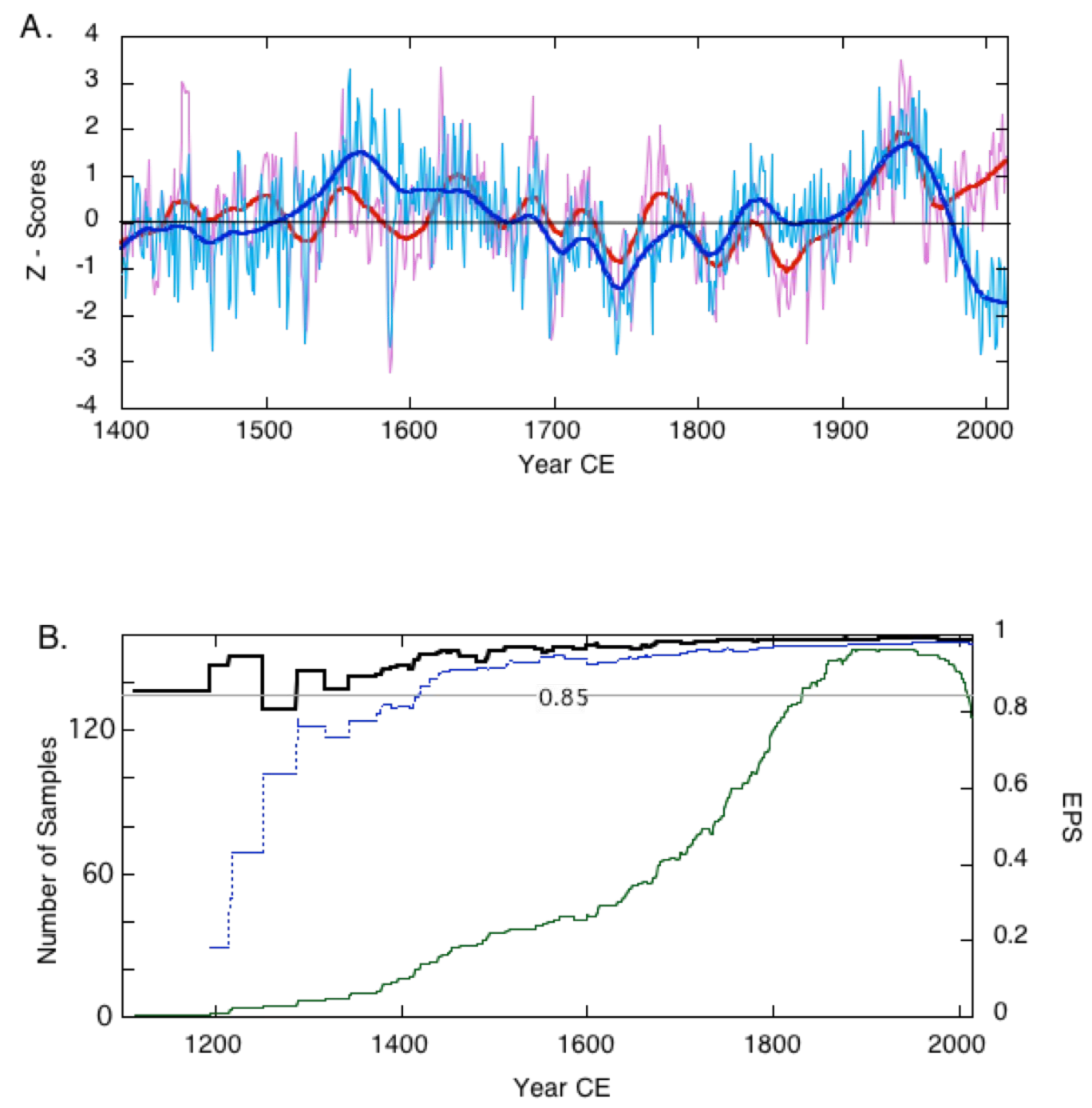

Fig. 2. (a) Z-scores (relative to the 1400-1900 interval) of the ring-width (red) and latewood blue intensity (YCLBi, blue) both chronologies are built from the composite of the three cedar sites (Figure 1). (b) Shows the sample size (green) and the EPS for each of the chronologies (black (RW) and blue (YCLBi). Note that the EPS statistic for both sites exceeds the critical 0.85 value about CE 1400. 

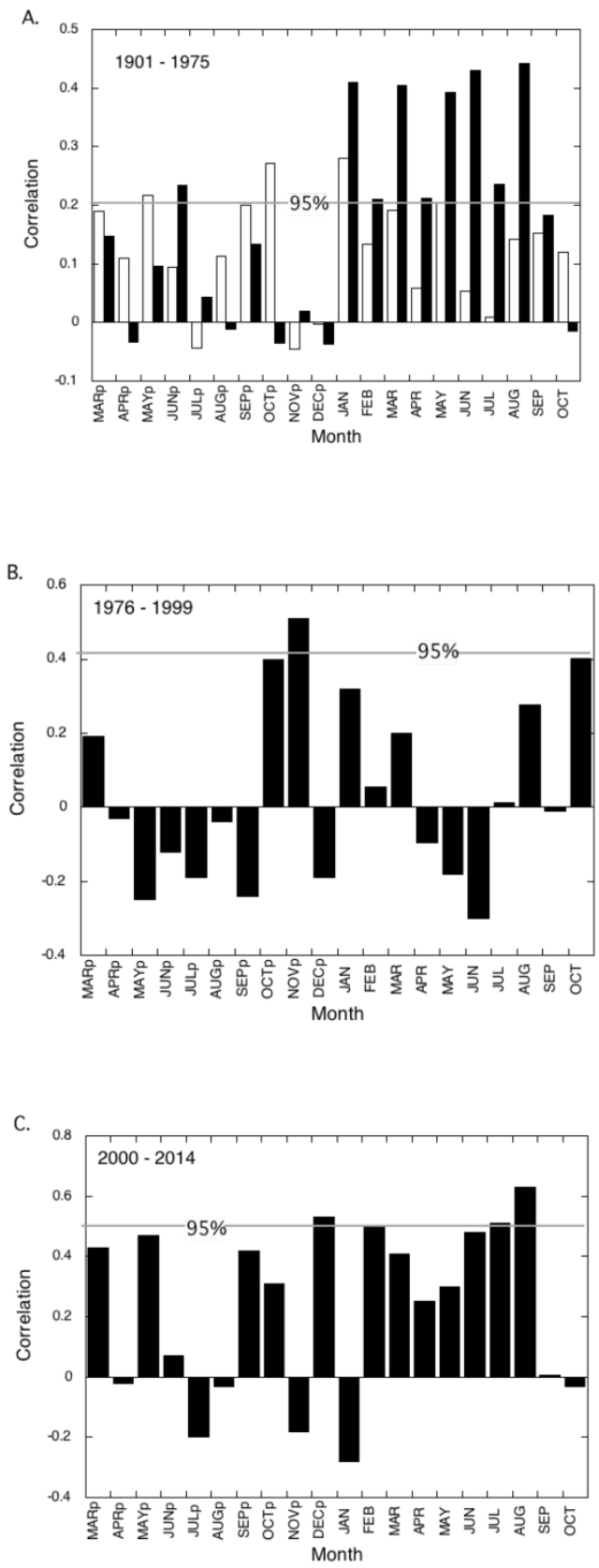

Fig. 3. (a) The temperature response (monthly correlations) for the ring-width (white) and blue intensity(black) cedar records for the dendroclimatic year. Note that for the 1901-1975 interval the YCLBi record correlates much more strongly with monthly temperatures than the RW. For the 1976-1999 interval, there is a significant loss of temperature sensitivity for YCLBi (b) and for the 2000-2014 interval correlations recover. The 95\% confidence level is shown for each data set. 

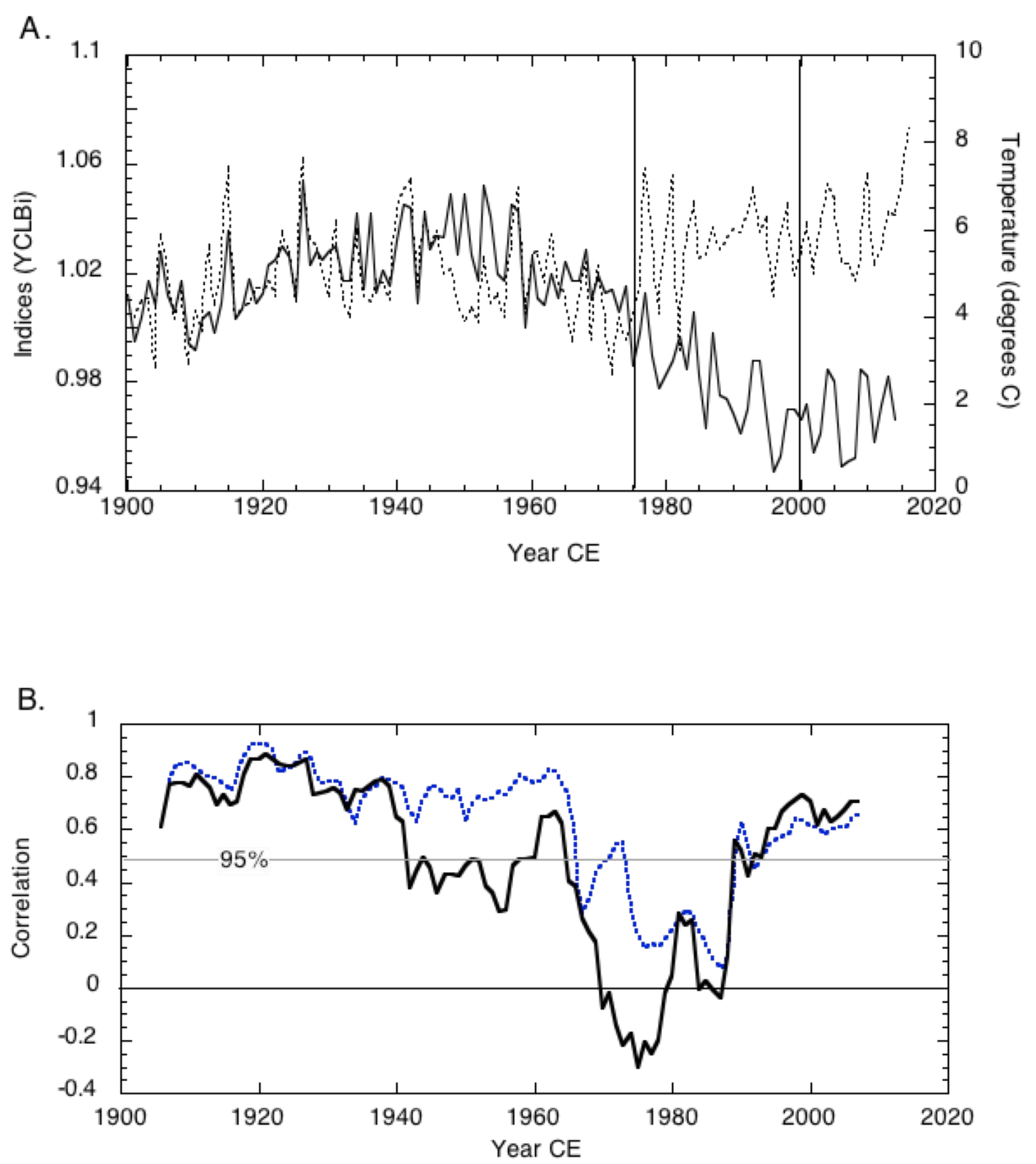

Fig. 4. Plots of (a) January through August average maximum temperatures (broken line) compared with YCLBI. Note how after 1975 the relationship diverges. (b) 15-year running correlations of the YCLBi series with maximum temperature (January-August average), with the non-transformed series (solid line) and with the first differenced data (broken line) showing the decadal loss of climate signal and then recovery. 


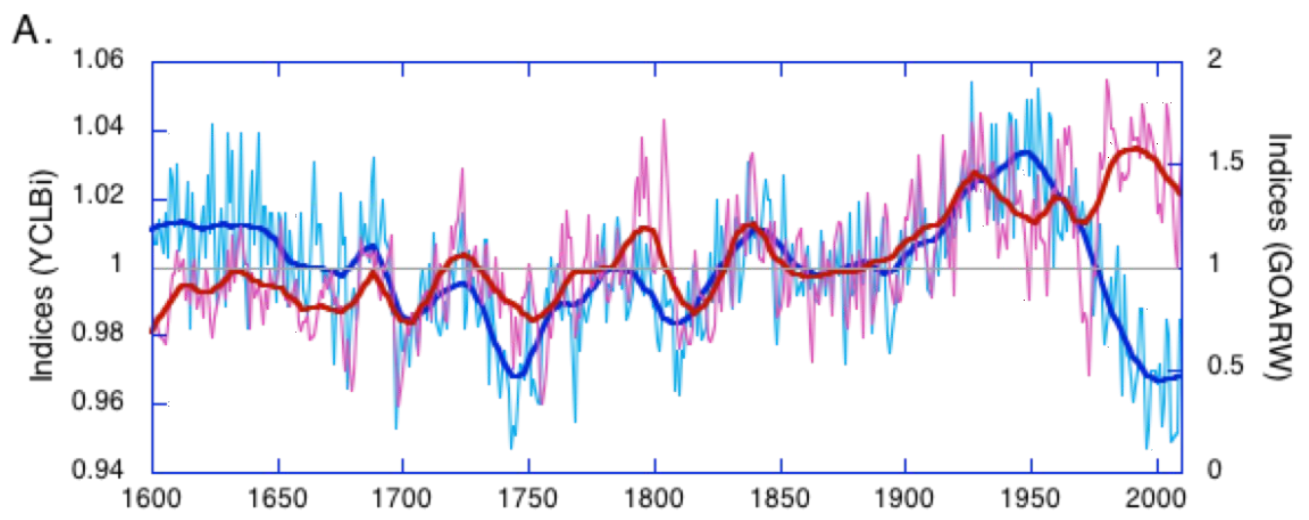

B.

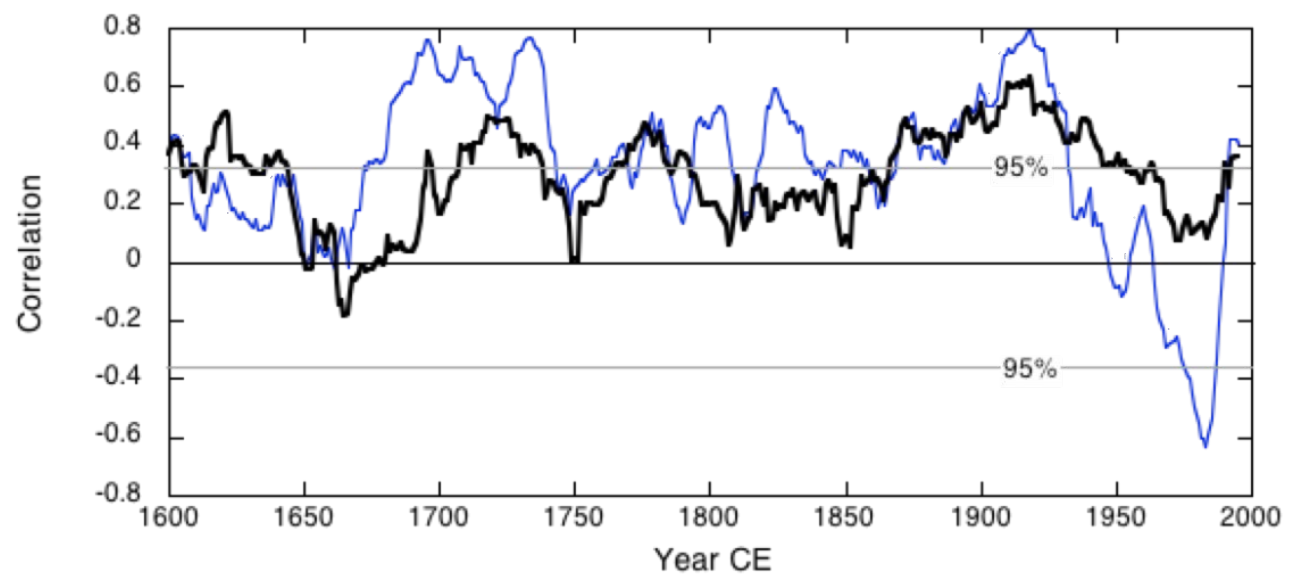

Fig. 5. YCLBi (blue) and GOARW (red) records compared. (a) Note the divergence of the two series in the last few decades. (b) 31-year running correlations between the two series (not transformed (blue) and the first differences (black). These running correlations show the dramatic drop in correlation after the 1976/77 regime shift in the North Pacific and a recovery in correlation after $\sim 1999$. 